\title{
JOHN F. KENNEDY DAN AHOK: KODE-KODE RETORIKA PEMIMPIN PUBLIK AGAMA MINORITAS
}

\author{
Desideria Cempaka Wijaya Murti \\ Universitas Atmajaya Yogyakarta, \\ email: desideriacempaka@gmail.com
}

\section{ABSTRACT}

Individual identity in politics is not a trivial matter. Identity is a signifier of meaning attached to a group. A Chinese politician will have a different symbolic meaning to majority of Indonesian people that considered him as foreigner. A similar case also occurred in the United States thata president is not only a leader of state and commander in chief during the war, but also as a symbol and ambassador for the country and the people who choose him. So that, it is feared that a leader from the minority is not able to become a symbol for the identities of the majority. Similar to Indonesia, a leader is expected to become a symbol for religion, ethnic, and tribal majority in the electoral area. However, with the current political developments, politicians from minority groups will have an "angel helper" because of the democratic system that separates religious affairs and public interest as well as the idea of equality and tolerance among religions.

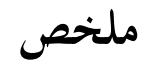

الهوية الفردية في السياسة ليست مسألة تافهة. الهوية هي الدال لمعنى يعلق على الجمموعة. السياسي الصيني لها معنى رمزي مختلف لأغلب الشعب الإندونيسيين الذين اعتبروه أجنبيا. حدثت حالة محاثلة أيضا في الولايات المتحدة أن رئيس الجمههورية ليس فقط قائدا للدولة وقائدا عاما خلال الحرب، ولكن أيضا باعتباره رمزا وسفيرا لهذا البلد وللناس الذين يختارونه. من هنا، يخشى أن زعيم من الأقلية ليس قادرا على أن بصبح رمزا للهوية الأغلبية. كما حدث في إندونيسيا، من المتوقع أن يصبحالقائد رمزا للدين وطائفة وأغلب القبائل في المنطقة الانتخابية. ومع ذلك، مع التطورات 


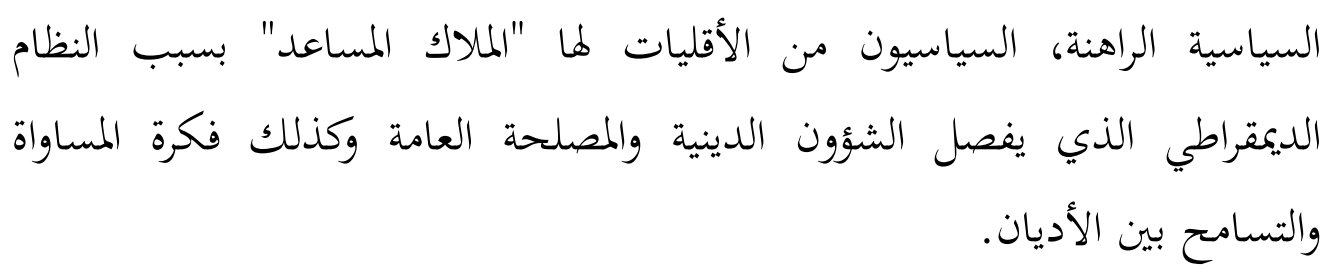

Key words: Identitas, pemimpin Negara, minoritas, makna simbolis.

\section{A. Pendahuluan}

I believe in an America that is officially neither Catholic, Protestant nor Jewish; where no public official either requests or accept instructions on public policy from the Pope, the National Council of the Churches or any other ecclesiastical source...John F Kennedy (American Rhetoric, 1960, hal. 2) ${ }^{1}$. (Saya percaya pada sebuah Negara Amerika, yang secara resmi bukan Negara Katolik, Protestan maupun Yahudi; dimana tidak ada institusi publik yang membuat aturan publik dan bersumber pada permintaan atau instruksi dari Paus, Konsel Nasional Gereja atau sumber-sumber kegerejaan lainnya).

Banyak yang tanya, kenapa milih Basuki? Ya, masyarakat di sana 93\% Muslim, lalu mereka bilang, Basuki itulah Islam, cuma dia belum dapet hidayyah jadi muslim... Basuki Tjahja Purnama (Kick Andy Youtube, 2011).

Dua pernyataan di atas adalah contoh pidato dua pemimpin yang berasal dari kelompok minoritas. John F Kennedy atau JFK adalah presiden terpilih Amerika Serikat pada tahun 1960 yang menang tipis atas Richard Nixon, yakni sebanyak 49.7\% dengan 49.6\%. ${ }^{2}$ JFK adalah seorang presiden Amerika Serikat yang fenomenal, seorang orator unggul, tetapi beragama Katolik Roma. Kristen Protestan adalah agama mayoritas di Amerika Serikat, sehingga isu agama menjadi isu SARA (suku, agama, dan ras) yang gencar disebarluaskan untuk membangun image anti-Katolik atau anti-Kennedy. Sementara, Basuki Tjahja

1 John Kennedy, "Address to the Greater Houston Ministerial Association" (American Rhetoric, September 12, 1960).

2 Barbara Warnick, "Argument Schemes and the Construction of Social Reality: John F. Kennedy's Address to the Houston Ministerial Association," Communication Quarterly 44, no. 2 (1996): hal. 183-196. 
Purnama atau Ahok adalah wakil gubernur Jakarta, yang mendampingi Gubernur Joko Widodo untuk periode 2012 hingga 2017. Sebelumnya, Ahok adalah Bupati Belitung Timur yang menang sebanyak 37.13\% pada tahun 2005. ${ }^{3}$ Kedua tokoh ini mengandalkan kode-kode retorik yang menarik bagi para pemilihnya. Kode ini menghasilkan pesona politik yang mampu mempersuasi audience serta membentuk image politik yang mempertegas identitas khas dari para pemimpin publik yang berasal dari kelompok minoritas.

Image politik merupakan bekal bagi para politisi untuk membentuk positioning dalam benak publik. ${ }^{4}$ Positioning ini tidak hanya dibangun dari platform program, tetapi juga identitas partai dan individu yang telah terekam dalam persepsi masyarakat. Celakanya, jika sebelum imagepolitikini dibentuk, publik sudah mengkotak-kotakkan individu tersebut. Misalnya, Amerika Serikat menggunakan strategi containment untuk mengasosiasikan individudengan komunis atau Uni Soviet. ${ }^{5}$ Jika strategi ini diletakkan pada seorang politisi, hasilnya bisa membuat pemilih takut karena politisi ini dianggap komunis, sehingga elektabilitasnya rendah. Indonesia, sebagai contoh lainnya, mungkin menerapkan kotak yang disebut "Cinanisasi" atau "Kristiniasasi." Sebuah kotak yang mengasosiasikan individu politik dengan etnis Tionghoa atau agama Kristiani. Jika persepsi masyarakat sudah terbentuk lebih dahulu, sebelum seorang politisi membangun image politik yang dia inginkan, maka jalan menuju pemilu akan sangat sulit dan menantang.

Identitas individu dalam politik bukan sebuah perkara yang sepele. Identitas merupakan sebuah penanda atau signifierdari makna yang melekat pada suatu kelompok. Seorang politisi keturunan Tionghoa akan memiliki makna simbolis yang berbeda terhadap keterwakilan masyarakat Indonesia yang masih menganggap etnis tersebut sebagai the other atau pendatang asing. Hal yang mirip juga terjadi di Amerika Serikat. Di Negara Paman Sam ini, presiden bukan hanya sekedar pemimpin Negara dan commander in chief saat perang, tetapi juga sebagai simbol dan duta bagi Negara tersebut dan rakyat yang memi-

3 “Basuki Cahya Purnama," Merdeka.com, (2012), http://profil.merdeka.com/ indonesia/b/basuki-tjahaja-purnama/ (Diakses pada 27 Maret 2013).

4 Al Rise dan Jack Trout, Positioning: The Battle for Your Mind. (New York: McGraw Hill, 1993).

5 Karrin Vasby Anderson, "“ Rhymes with Blunt': Pornification and US Political Culture," Rhetoric \& Public Affairs 14, no. 2 (2011): hal. 327-368. 
lihnya. ${ }^{6}$ Sehingga pemimpin dari minoritas ditakutkan tidak mampu menjadi simbol bagi identitas para pemilih yang berasal dari kelompok mayoritas. Sama halnya dengan Indonesia, seorang pemimpin diharapkan menjadi simbol bagi agama, etnis, dan suku mayoritas di area pemilihan. Pemimpin dari kelompok minoritas ditakutkan tidak dapat membawa simbol ini serta tidak mampu memahami kebutuhan mayoritas. Tetapi, dengan perkembangan politik saat ini, politisi dari kelompok minoritas akan memiliki "malaikat penolong" yakni sistem demokrasi yang memisahkan urusan agama dan kepentingan publik serta ide persamaan hak dan toleransi antar agama.

Perdebatan yang sering muncul ketika individu dari minoritas ingin ikut dalam pemilihan umum adalah representasi simbol dan identitas. Kedua variabel ini merembet menuju embel-embel lain seperti kemampuan pemimpin dalam memenuhi kebutuhan publik (baca: mayoritas), cara berkomunikasi sesuai dengan keinginan mayoritas, kepercayaan, budaya, dan lain-lain. Tetapi, makna berdemokrasi, yakni equality atau persamaan hak bagi warga Negara untuk terlibat langsung dalam urusan kenegaraan, hukum, pemilihan umum, dan perundang-undangan, mampu memberikan ruang bagi individu dari minoritas untuk terjun dalam politik praktis. ${ }^{7}$ Selain itu, sekalipun identitas pemimpin minoritas itu tidak sama dengan mayoritas, tetapi tidak berarti individu ini lemah dalm memfasilitasi kebutuhan publik. Jika kontrak sosial masyarakat mampu terpenuhi melalui platform program yang menjanjikan seperti pemenuhan kebutuhan dasar dan peningkatan kehidupan rakyat, maka ada justifikasi politis untuk berargumen bahwa pemimpin dari kelompok minoritas dapat dipilih. Tetapi, diperlukan kode-kode dan strategi komunikasi yang jitu untuk menegosiasikan identitas ini dan bahkan mendobrak kotak persepsi masyarakat.

Kode-kode retorika dalam pembentukan image politik dapat dilakukan dalam berbagai kesempatan dan ruang publik yang disediakan di arena demokrasi. Misalnya dalam pidato formal, non-formal, tulisan di media massa, wawancara dengan media, sarasehan dengan warga, dan lain-lain. Retorika sendiri adalah sebuah kajian dalam seni wicara atau tulisan dengan tujuan untuk mem-

6 Martin J. Medhurst, "Mitt Romney,' Faith in America,' and the Dance of Religion and Politics in American Culture," Rhetoric E Public Affairs 12, no. 2 (2009): hal. 195-221.

7 "The Nature of Government," American Government. (2008-2013).http://www.ushistory.org/gov/1d.asp (Diakses pada 23 Mei 2013). 
persuasi. ${ }^{8}$ Sejak dikembangkan oleh Aristoteles, mengkaji sebuah teks retorika menjadi populer di kalangan akademisi terutama dalam tradisi pendidikan di Negara barat, khususnya Amerika Serikat. ${ }^{9}$ Kode, dalam istilah penulis merupakan pola atau tanda dalam bahasa yang ditemukan dalam eksplorasi sebuah kajian retorika. Kajian ini akan membuka wacana mengenai metode komunikasi yang dipakai oleh individu dalam mempersuasi publik.

Para pemimpin dari kelompok minoritas ini tentu memiliki strategi dalam menyampaikan pesan politik berkaitan dengan identitasnya. Melalui pesan-pesan politis tersebut, dekonstruksi kode-kode retorika dapat dilakukan. Dalam tulisan ini, akan dibahas secara spesifik mengenai contoh kode-kode retorika dalam beberapa pidato pemimpin dari kelompok minoritas khususnya melalui identitas agama. Analisis ini menggunakan contoh pidato John F Kennedy dan mengaplikasikan kode-kode retorikanya dalam kasus Basuki Tjahja Purnama atau Ahok. Kode retorika yang digunakan oleh pemimpin publik dari agama minoritas adalah kode pemisah atau diasosiasi dan kode persamaan hak serta toleransi antar agama. Untuk itu akan dijabarkan, pertama, mengenai pentingnya kode-kode retorika dalam pembentukan image politik. Kedua, akan dikemukakan lebih lanjut mengenai agama dan pergesekannya dengan politik. Ketiga, contoh kode-kode retorika yang ditampilkan oleh politisi dari kelompok minoritas sebagai strategi komunikasi publik akan dianalisis dan diaplikasikan sesuai dengan konteks Indonesia. Pemimpin publik dari agama minoritas tidak hanya memperkaya diskursus publik dalam politik tetapi juga mampumengedukasi praktek berdemokrasi bagi masyarakat luas.

\section{B. Kode-kode Retorika dalam Politik}

Dunia politik tidak lepas dari pembahasan mengenai strategi penggunaan bahasa dan kata-kata yang mampu membangun persepsi bagi publik. Bahkan kata-kata implisit dan eksplisit dalam suatu pidato politik mampu membawa dimensi makna yang berbeda. ${ }^{10}$ Penggunaan kata-kata dan pembahasaan yang

\footnotetext{
8 "What is Rhetoric?" Bringham Young University. (http://rhetoric.byu.edu/encompassing\%20terms/rhetoric.htm (Diakses pada 20 Mei 2013).

9 "What is Rhetoric?" Bringham Young University. (http://rhetoric.byu.edu/encompassing\%20terms/rhetoric.htm (Diakses pada 20 Mei 2013).

10 Medhurst, "Mitt Romney,' Faith in America,' and the Dance of Religion and Politics in
} 
strategis dan taktikal mampu membangun opini penonton bahkan sampai ke tingkat yang paling fluid sekalipun yakni opini dunia internasional terhadap suatu Negara. ${ }^{11}$ Presiden RI pertama yakni Soekarno, dikenal sebagai orator yang to the point, provokatif, berapi-api, dan menggunakan bahasa yang mudah dimengerti. Bahkan kata, "Ganyang Malaysia” pun sampai sekarang masih dikumandangkan oleh beberapa kelompok masyarakat. Kekuatan oratorik seseorang mampu menggerakkan massa, membawa pesan dari generasi ke generasi, dan membangun kekhasan image dan identitas politik seseorang.

Kajian retorika menjadi salah satu cara untuk menemukan pola strategi komunikasi politik yang digunakan oleh individu. Amerika Serikat sendiri mengembangkan kajian retorika berkaitan dengan pesan-pesan penting yang disampaikan oleh politisi, aktivis, maupun presiden. Misalnya pidato "Nuclear for Peace (Nuklir untuk Perdamaian)" milik Eisenhover digunakan untuk secara diplomatis mencegah Uni Soviet untuk melancarkan serangan nuklir. ${ }^{12}$ Pidato "Starwars (Perang Bintang)" milik Ronald Reagan digunakan juga untuk memberikan statement dan posisi Amerika Serikat dalam perang terhadap komunis. ${ }^{13}$ Hingga pidato "The war on terror (Perang terhadap Teror)" dari George W Bush untuk menanggapi penyerangan 11 September. Semua didokumentasikan sebagai inventoris politik yang penting dan dibedah oleh para ahli komunikasi. Kajian retorika memampukan masyarakat untuk berpikir kritis dan tidak mudah dibodohi dengan permainan kata politisi. Dalam tulisan ini, penulis juga ingin mengajak pembaca untuk melihat fenomena komunikasi politik yang sering disampaikan oleh para pemimpin khususnya pemimpin rakyat dari agama minoritas di suatu area atau Negara.

Agama dan politik sering bersandungan satu dengan yang lain. Agama terkadang mampu memberikan kekuatan politik bagi suatu kelompok atau individu. Dalam pidato politik sering ditemukan individu menggunakan ayat-

American Culture."

11 Ibid.; Paul Fessler, "Ronald Reagan, Address to the National Association of Evangelicals ('Evil Empire Speech' 8 March 1983)” (2009), http:/ / archive.vod.umd.edu/ documents/ Fessler-Reagan.pdf.

12 Medhurst, "Mitt Romney,' Faith in America,' and the Dance of Religion and Politics in American Culture."

13 Fessler, "Ronald Reagan, Address to the National Association of Evangelicals ('Evil Empire Speech') (8 March 1983)" 
ayat suci, kutipan kitab suci, bahkan cara berpidato yang mendekati "nabinabi" tertentu. Fenomena ini sangat biasa di Indonesia dan di Negara-negara yang memiliki "garis abu-abu" untuk membatasi agama dan negara. Tetapi bagaimana dengan para pemimpin dari agama minoritas? Akankah mereka menggunakan ayat-ayat suci ini untuk membangun image mereka? Mampukah retorika agama mereka membaurkan identitas mereka dengan masyarakat dari kelompok minoritas?

\section{Agama dan Identitas Figur politik}

Agama dan identitas menjadi faktor penting dalam berpolitik. Apalagi di Indonesia yang notabene merupakan Negara yang berlandaskan pada "Ketuhanan yang Maha Esa," yang sering diartikan bahwa orang Indonesia "harus" punya agama. Contoh kecil misalnya, Kartu Tanda Penduduk (KTP) yang berisi kolom agama. Kecil kemungkinan seseorang mengisi kosong pada kolom tersebut, sebab konsekuensi birokrasi dan administratif untuk berbagai keperluan sipil akan sulit jika kolom "ajaib" itu kosong atau tidak beragama. Banyak pula politikus yang menggunakan tameng agama sebagai cara untuk membangun identitas politik. Misalnya, pada saat bulan puasa atau mendekati lebaran, tibatiba saja muncul baliho dan spanduk politikus yang tampak agamis. Menggunakan attire keagamaan seperti peci dan baju koko atau kerudung, lalu menyapa dengan santun agar terlihat agamis. Fenomena sosial ini menunjukkan betapa agama memegang peranan penting dalam membangun image politik seseorang.

Tidak hanya di Indonesia, di luar negeri pun, sering sekali agama, atau ajaran agama menjadi cara untuk berkomunikasi dan berpolitik. Misalnya pada pidato pada 18 Maret 2008, Obama tercatat berpidato untuk memberikan tanggapan atas kotbah Pastor Jeremiah Wright dari Gereja Trinity Church of Christ yang sangat kontroversial dan menjelek-jelekkan nilai dan perilaku pemerintah Amerika Serikat. ${ }^{14}$ Dalam kotbah itu, Obama dibela oleh Pastor Jeremiah tetapi pada waktu yang bersamaan pastor itu menghina Hillary Clinton sebagai perempuan kulit putih pesaing Obama dalam konvensi Partai Demokratik.

14 David A. Frank, "The Prophetic Voice and the Face of the Other in Barack Obama's' A More Perfect Union' Address, March 18, 2008," Rhetoric \& Public Affairs 12, no. 2 (2009): hal. 167-194. 
Salah satu kotbah Pastor Wright yang sangat kontroversial misalnya: Not "God Bless America"; God Damn America! That's in the Bible, for killing innocent people. God Damn America for treating her citizens as less than human. God Damn America as long as she keeps trying to act like she is God and she is supreme! ${ }^{15}$ (Bukan "Tuhan Memberkati Amerika"; Tuhan Mengutuk Amerika! Itulah yang ada dalam Alkitab, untuk mereka yang membunuh manusia yang tidak bersalah. Tuhan mengutuk Amerika karena memperlakukan masyarakatnya (Penggunaan kata masyarakatnya, "nya" sebagai kata ganti milik Amerika, dengan kata "her" yakni milik wanita) dengan tidak berperikemanusiaan. Tuhan Mengutuk Amerika selama ia (menunjuk kata ganti wanita, yakni "she") tetap bertidak seolah-olah ia (menunjuk kata ganti wanita, yakni "she") adalah Tuhan dan ia lebih berkuasa).

Khotbah ini dianggap seksis dan rasis, tetapi Obama diuntungkan dalam khotbah ini. Oleh sebab itu Obama berusaha untuk menjaga reputasinya sebagai calon presiden dengan strategi retorika yang bisa mendekatkan dialog antarras dan sekaligus menggunakan pidato prophetic atau pidato yang menggunakan cara berkhotbah para nabi dalam Alkitab. Misalnya:

The profound mistake of Reverend Wright's sermons is not that he spoke about racism in our society. It's that he spoke as if our society was static, as if no progress has been made, as if this country - a country that has made it possible for one of his own members to run for the highest office in the land and build a coalition of white and black, Latino and Asian, rich and poor, young and old - is still irrevocably bound to a tragic past. But what we know-what we have seen-is that America can change. That is the true genius of this nation. ${ }^{16}$ (Kesalahan terbesar Pendeta Wright adalah bukan karena ia berbicara tentang rasisme dalam masyarakat kita. Kesalahannya adalah bahwa ia berbicara seolah-oleh masyarakat kita adalah masyarakat yang statis, seolah tidak ada progress yang telah dibuat, seolah bahwa Negara ini -- sebuah Negara yang mampu membangun koalisi antara hitam dan putih, Latin dan Asia, kaya dan miskin, tua dan mudamasih merupakan Negara yang terikat pada masa lalu yang tragis. Tetapi kita tahu bahwa Amerika bisa berubah. Itulah kejeniusan sebenarnya dari Negara ini.)

15 Jeremiah A. Wright, "Confusing God and Government," http://www.blackpast. org/?q=2008- rev-jeremiah-wright-confusing-god-and-government (accessed October 14, 2008).

16 Frank, "The Prophetic Voice and the Face of the Other in Barack Obama's' A More Perfect Union' Address, March 18, 2008." 
Obama, dengan sukses mampu menggabungkan teologi yang berkembang dari sudut africentric dengan tradisi Yahudi, dan Kristen. Melalui strateginya dalam menggunakan retorika antara agama dan politik, Obama membangun image sebagai pemersatu suatu Negara dan sekaligus menggunakan pendekatan berpidato yang menggunakan pendekatan fenomenologis dan hermeneutics seperti ketika Nabi Musa bercerita tentang kesalahan suatu bangsa. ${ }^{17}$

Kembali ke Indonesia. Di Indonesia pembahasan mengenai pidato atau perkataan seorang politisi dalam membangun image menggunakan tameng agama, tidak dapat sepenuhnya dikatakan sebagai pendekatan hipokrit. Tetapi, strategi retoris dengan menggabungkan antara content atau isi dengan relationship atau hubungan mereka sebagai politisi dari kaum minoritas bisa jadi menjadi cara satu-satunya bagi mereka untuk bisa diterima oleh publik. Ini berhubungan erat dengan aksioma dalam komunikasi yakni komunikasi adalah tentang isi dan hubungan. ${ }^{18}$ Ini berarti, isi dari suatu pidato atau alat komunikasi harus disesuaikan dengan hubungan pembicara dengan penerima pesan. Ini disebabkan persepsi yang ditimbulkan oleh isi suatu pesan komunikasi bisa berbeda, jika hubungan penyampai dan penerima pesan berbeda. Misalnya seorang pemimpin Kristiani mengatakan kalimat seperti, "Gereja memiliki kelemahan karena terlalu hirarkis" akan diterima sebagai kritik internal oleh sesama pemeluk agama atau masyarakat umum yang mendengarnya. Kritik internal ini akan dipersepsikan lebih soft daripada jika seorang pemimpin Muslim yang mengatakan, "Gereja memiliki kelemahan karena terlalu hirarkis." Kalimat yang disampaikan oleh pemimpin Muslim ini akan dianggap sebagai kritik eksternal yang bisa dianggap sebagai penghinaan terhadap suatu agama. Kata-kata yang memiliki isi yang sama tetapi dilontarkan oleh penyampai pesan dengan hubungan yang berbeda akan memiliki persepsi yang berbeda. Demikian pula dengan pemimpin publik yang berasal dari agama minoritas, mereka perlu berhati-hati dalam menyampaikan pesan agar tidak dianggap sebagai kritik eksternal dan penghinaan agama. Oleh sebab itu terdapat beberapa kode-kode yang biasa dilakukan oleh pemimpin publik yang memiliki agama minoritas.

17 Ibid.

18 Paul Watzlawick, Beavin-Bavelas, J., Jackson, D. Some Tentative Axioms of Communication. In Pragmatics of Human Communication - A Study of Interactional Patterns, Pathologies and Paradoxes. (New York: W. W. Norton, 1967). 
Tulisan ini membahas beberapa contoh aplikasi dari kode-kode yang pernah dideteksi dalam pidato John F Kennedy ${ }^{19}$ yang digunakan untuk menjembatani perbedaan agama yang dimiliki oleh pemimpin publik itu. Konsep dan teori ini diambil dari deteksi strategi retorika dari tokoh Amerika Serikat sebab deteksi semacam ini belum populer di Indonesia. Bisa jadi malah belum banyak dilakukan dan bahkan belum ada framework teorinya. Harapannya, dengan meminjam perspektif barat ini, diharapkan dapat dilihat konteksnya di Negara timur yakni Indonesia. Kode-kode itu antara lain kode pemisahan atau separation code, yang berupa diasosiasi dan kode reciprocity atau pertukaran, dimana kode ini berisi kode persamaan hak dan toleransi agama. Kontekstulisasi teori dan konsep retorika ini juga akan dihubungkan dengan budaya dan kondisi di Indonesia. Harapannya, tulisan ini dapat memberikan khasanah yang luas mengenai pendekatan retorika dalam fenomena politik di Indonesia.

\section{Kode Pemisahan}

\section{Konteks di Amerika Serikat}

Pada pemilu Presiden tahun 1960 di Amerika Serikat, Senator partai Demokrat John F Kennedy memenangkan voting sebesar $49.7 \%$ saat melawan Richard Nixon. Bukan pertarungan yang mudah sebab mereka telah memperdebatkan berbagai macam isu seperti persenjataan nuklir, pendidikan, dan hak asasi manusia. Tetapi isu lain juga berkembang pesat yakni isu yang menyangkut agama. Kennedy menjadi satu-satunya kandidat Presiden yang beragama Katolik Amerika Serikat. Belum pernah ada Presiden beragama Katolik sebelumnya dalam sejarah AS.

Kampanye anti pemimpin minoritas juga telah terjadi di Amerika Serikat sejak dahulu. Pamflet, buku, dan spanduk anti katolik banyak disebarkan pada masa kampanye Kennedy versus Nixon. Tetapi pada pidato-pidato kampanyenya, Kennedy mampu membuat kode retorika yang mempesona publiknya dan sangat persuasif, sehingga membuat publik percaya dan memilih Kennedy sebagai satu-satunya Presiden beragama Katolik. Kennedy mampu memisahkan kemampuannya untuk mengurusi kepentingan publik dengan urusan privat keagamaannya. Kennedy juga dianggap mampu menempatkan diri sebagai

\footnotetext{
19 Warnick, "Argument Schemes and the Construction of Social Reality."
} 
pendengar, menanggapi lawannya, menekankan prinsip-prinsip kerjanya, dan penegasannya mengenai jarak yang akan dia buat antara urusan Amerika Serikat dan Vatikan.

\section{Pidato Kennedy dan Kode Pemisahan}

John F Kennedy membuat pidato-pidato yang menakjubkan, sekaligus sangat strategis yang beguna untuk menyampaikan posisinya sebagai kandidat Presiden dan seorang individu yang beragama Katolik. Kennedy menjawab pertanyaan tentang milik siapakah dia? Milik publik atau milik gereja Katolik. Salah satu strateginya yang terkenal disebut dengan kode diasosiasi. Kode ini mampu membedakan antara instruksi yang berhubungan dengan moral, keimanan, dan instruksi yang berdasarkan kepentingan publik. ${ }^{20}$ Kode disasosiasi adalah strategi yang mampu membuat audiens membedakan posisi personal seorang individu dan posisi publik seorang pejabat. Kode retorik yang berupa diasosiasi juga membuat penonton mampu membedakan antara penampilan (Appearance) yang berhubungan erat dengan persepsi dan realitas (Reality) yang berhubungan erat dengan kebijakan, nilai, dan aturan yang dapat dinilai.

Pidato Kennedy yang mampu menunjukkan kode diasosiasi ini misalnya adalah "...state once again-not what kind of church I believe in, for that should be important only to me - but what kind of America I believe in." 21 (Negara sekali lagi - bukan tentanggereja apa yang aku percaya, yang mana itu hanya penting untukku saja - tetapi Amerika seperti apa yang aku percaya). Pernyataan tersebut adalah sebuah strategi diasosiasi yang memisahkan antara isu keagamaan dan isu yang sebenarnya yang lebih universal. Kennedy juga mengisolasi identitasnya dengan membedakan antara posisi publiknya dan identitas pribadinya, misalnya dengan pernyataan seperti "I am not the Catholic candidate for President. I am the Democratic party's candidate for President who happens also to be a Catholic." 22 (Saya bukan kandidat Katolik untuk Kepresidenan. Saya adalah kandidat Presiden Partai Demokrat yang kebetulan adalah seorang Katolik). Melalui pernyataannya ini, Kennedy sedang bermain dengan strategi tarik ulur antara identitasnya sebagai orang Katolik dan di saat yang bersamaan memi-

\footnotetext{
${ }^{20}$ Ibid.

${ }^{21}$ Kennedy, "Address to the Greater Houston Ministerial Association."

22 Ibid.
} 
sahkan isu agama Katolik yang tunduk dengan perintah Vatikan. Kennedy, sebagai pemimpin dari kelompok minoritas, berusaha memisahkan isu keagamaannya dalam usahanya meraih jabatan publik. Di satu sisi, ia tetap mengakui identitas privatnya sebagai seorang dengan agama minoritas. Selain itu, Kennedy mencoba membawa intersectional identity ${ }^{23}$ atau identitas yang beririsan dengan identitas lainnya, sehingga bisa mendekatkan identitas minoritasnya dengan identitas mayoritas. Misalnya, Kennedy adalah seorang Katolik, tetapi juga memiliki identitas yang lain dan sama dengan identitas mayoritas yakni, Ia adalah seorang warga Negara Amerika Serikat, seorang pria kelas menengah ke atas, seorang berkulit putih, dan seorang berpikiran liberal. ${ }^{24}$ Biar bagaimanapun juga, tidak ada seorang individu yang hanya memiliki satu identitas saja. Pasti ada irisan identitas yang dimilikinya, yang sama dengan orang lain. Inilah yang berusaha ditonjolkan oleh Kennedy. Sehingga, jika pun ada perbedaan dalam identitas minornya, perbedaan ini dapat disamarkan dengan persamaan yang dimilikinya dengan publik mayoritas.

\section{Konteks di Indonesia}

Kemenangan kampanye bersama Jokowi melawan Fauzi Bowo yakni sebesar 53, 81 \% sementara pesaingnya Fauzi Bowo dan Nachromi Ramli mendapatkan 46, 91\%, Basuki Tjahja Purnama atau Ahok tetap mendapat berbagai serangan isu SARA. ${ }^{25}$ Pada saat pemilu, isu SARA cukup gencar terjadi untuk menyerang Ahok, dan bahkan sesudah pemilihannya. Isu yang memperdebatkan mengenai agama dan etnis dilontarkan oleh kubu Foke-Nara saat debat gubernur dan juga dilontarkan oleh pemuka agama dan masyarakat yakni Rhoma Irama. ${ }^{26}$

23 Cherrie Moraga and Gloria Anzaldua, This Bridge Called My Back. (New York: Women of Color Press, 1981).

${ }^{24}$ Chaim Perehnan and Lucie Olbrechts-Tyteca, The New Rhetoric: A Treatise on Argumentation, frans. John Wilkinson and Purcell Weaver (Notre Dame: U of Nofre Dame P, 1969): hal. 187-459.

25 Kurnia Sari Aziza, “LSI: Jokowi Basuki 53,81 persen dan Foke-Nara 46,19 persen, ” Kompas.com(20September2012),http:/ / megapolitan.kompas.com/read/2012/09/20/20285279/ LSI.Jokowi-Basuki.53.81.persen.Foke-Nara.46.19.persen (Diakses pada 5 September 2013).

26 "Sudutkan Jokowi Ahok, Rhoma Irama dipanggil Panwaslu," JPPN.com (1 Agustus 2012), http://www.jpnn.com/read/2012/08/01/135539/Sudutkan-Jokowi-Ahok,-Rhoma-Irama-Dipanggil-Panwaslu- (Diakses pada 5 September 2012). 
Hingga saat ini Ahok adalah satu-satunya wakil gubernur Jakarta yang beretnis Tionghoa sekaligus beragama minoritas, yakni agama Kristen.

Pada masa kampanye, gerakan anti Ahok, anti Cina, dan bahkan anti Kristen juga terjadi di Jakarta. Dengan memanfaatkan ruang publik seperti masjid, pertemuan kampung hingga RT dan RW, bahkan selebaran banyak disebarkan pada masa kampanye pemilu gubernur. Tetapi dengan kekhasan gaya Ahok yang blak-blakan, to the point, dan tidak suka basa-basi, Ahok mampu membuat kode retorika yang "mengamankan" posisinya sebagai calon pemimpin publik dari kelompok agama minoritas. Mirip dengan JFK, Ahok membuat beberapa statement atau pernyataan dalam pidato publik, konferensi pers, hingga wawancara di media massa yang menggunakan kode retorika. Meskipun tidak terstruktur seperti JFK, dan dengan gaya Ahok yang lebih slengekan, Ahok membuat kemiripan pola komunikasi politik. Kode diasosiasi atau kode pemisahan juga dibuat oleh Ahok dengan menggunakan berbagai simbol retorik, dan pernyataan yang kuat untuk meyakinkan publik bahwa sebagai pejabat publik, Ahok mampu memisahkan kepentingan privatnya dengan kepentingan publik.

\section{Pidato Basuki Tjahja Purnama dan Kode Pemisahan}

Dalam berbagai kesempatan, Ahok menggunakan kode retorika yang berusaha memberikan edukasi kepada publik untuk memisahkan kepentingan publik dan kepentingan privat atau agama. Ahok menjawab pertanyaan mengenai apakah ia milik publik atau milik agama Kristen. Kode ini membedakan penampilan identitasnya dan hubungannya dengan kebijakan dan prinsip-prinsip untuk memerintah suatu area. Kode pemisahan ini dapat disampaikan secara eksplisit maupun simbolis. Tentu dengan gaya blak-blakan Ahok dan tanpa tedeng aling-aling, Ahok menyampaikan kode diasosiasi. Data ini diperoleh dari berbagai dokumentasi pidato Ahok yang sporadik dan tidak dalam konteks yang sama. Pidato ini diperoleh dari dokumentasi di berbagai media massa yang luas. Salah satu kode disasosiasi ini misalnya:

Saya terus terang menganut prinsip membedakan antara agama dan negara. Tapi saya tetap bersikap dan bertindak tetap sesuai dengan nilai dan norma agama saya. Itu yang penting. ${ }^{27}$ 
Secara eksplisit, Ahok mengungkapkan nilainya yang membedakan kepentingan privat agamanya dan kepentingan publik. Pernyataan tersebut menunjukkan prinsip atau nilai individu yang dianutnya sebagai kontrak sosial terhadap pemilih dari kelompok yang berbeda agama dan lebih mayoritas. Di satu sisi, Ahok juga mengakui bahwa nilai-nilai agama yang dianutnya membawa kesadaran tertentu dalam kaedah norma dan nilai kemanusiaan. Ahok bermain tarik ulur pula dengan mengakui pengaruh agama dalam kehidupannya dan kesadaran nuraninya, tetapi di saat yang bersamaan mengungkapkan kemampuannya membedakan kepentingan agama dan Negara. Dalam kesempatan yang lain, Ahok juga mengungkapkan radikalismenya terhadap prinsip dan nilai yang dimilikinya. Tidak seperti JFK yang lebih simbolik, Ahok tampak cukup to the point dan blak-blakan dalam prinsipnya. Salah satu pernyataannya yang cukup menghebohkan misalnya:

Saya tidak akan mengatakan karakter saya seperti apa, tapi saya akan menunjukkan bahwa saya hanya taat sama konstitusi, bukan konstituen. Kalaupun saya harus mati, saya siap untuk konstitusi. ${ }^{28}$

Kalimat ini memang banyak diplintir oleh berbagai media massa sehingga menimbulkan kontroversi yang cukup besar. Tetapi dari kalimat ini dapat terlihat teknik disasosiasi yang dilakukan oleh Ahok. Sama seperti JFK, Ahok menghubungkan prinsipnya sebagai individu yang memiliki ruang privat dengan prinsip kenegaraannya yang membuatnya harus tunduk dengan konstitusi sebagai warga Negara yang baik.

Ada tokoh agama yang bilang sama saya, "Ahok kamu pasti nggak ada yang ngalahin, tapi cuma satu, karena disini 90\% Islam, Masyumi, kamu jadi mualaf saja, kamu pasti menang." Lalu saya bilang, Abah bilang saya bagus. Ok, Abah tahu kenapa bagus? Karena saya tahu ada Tuhan, saya tidak berani berbuat yang tidak baik. Kalau saya ngakalin Tuhan hanya karena sekedar saya dapat jabatan ini, nah abah hati-hati, karena jabatan itu pula, saya pun bisa makan teman sendiri. ${ }^{29}$

Dalam dialognya dengan para pemuka agama ini, Ahok mampu menunjukkan kemampuan individu menyaring pertimbangan yang bersifat privat

${ }^{28}$ Heri Purnomo, “Ahok: Antara Konstitusi, Kitab Suci dan Konstituen, " Kompasiana (27 Agustus 2013), http://sosok.kompasiana.com/2013/08/27/ahok-antara-konstitusi-kitabsuci-dan-konstituen-587588.html (Diakses pada 7 September 2013).

29 "Ahok: Alasan saya tidak pindah agama Islam karena...," Youtube, (21 Juli, 2013), https://www.youtube.com/watch?v=35v6NgIcx18 (Diakses pada 7 September 2013). 
dengan pertimbangan prakmatis karena suatu jabatan publik tertentu. Integritas dalam kode retorika pemisahan ini sangat jelas ditunjukkan tanpa melupakan identitas pribadinya yang memiliki kepercayaan tertentu.

\section{E. Kode Persamaan Hak dan Toleransi Agama}

\section{Konteks di Amerika Serikat dan Credo}

Dalam berbagai pidato politiknya, JFK sering disebut-sebut sebagai seorang jenius, yang secara simbolis mampu menggabungkan unsur keagamaannya namun pada saat yang sama memberikan pemisahan terhadap isu agama dalam politik. JFK disebut sebagai seorang orator yang sedang berkotbah, atau yang disebut sebagai pidato sermonic. Menggunakan bentuk sermonic atau mirip kotbah, Kennedy mengartikulasikan doktrin diikuti dengan aplikasi dari suatu kondisi riil dan fenomena sosial yang dirasakan langsung oleh masyarakat. Audience atau penonton yang tertarik dengan pidato ini, baik tertarik secara positif atau menghina Kennedy adalah para pemuka agama dan tokoh yang peduli dengan agama, iman, akhlak, dan sejenisnya. Misalnya Kennedy menggunakan kata "I believe in..." atau "Aku percaya akan...." Sebuah kata yang sangat khas dalam agama Katolik. ${ }^{30}$ Sebuah Credo atau kalimat syahadat yang diucapkan oleh umat Katolik pada setiap acara puncak iman yakni Upacara Misa atau Perjamuan Ekaristi. ${ }^{31}$ Kata "Aku percaya akan..." ini sangat khas Katolik dan tidak diucapkan atau tidak menjadi kekhasan agama lain seperti Kristen Protestan, tetapi justru menjadi kejeniusan Kennedy dalam berpidato. Ciri khas ini justru digunakan oleh Kennedy untuk menunjukan sermonic quality atau kualitas kotbah dalam pidatonya. ${ }^{32}$ Tetapi, la menggunakan kalimat lanjutan yang justru sangat universal untuk menggabungkan identitasnya sebagai umat minoritas tetapi juga umat mayoritas. Kennedy menggantikan "Eclesial Credo" dari kata "Credo in unum Deum" (Aku percaya akan Allah), yang berasal dari doktrin Katolik menjadi "Credo in..." (Aku Percaya akan...)." Sangat Katolik, tetapi juga menjadi sangat universal, mengakui Kekatolikan tetapi di saat yang bersamaan memisahkan diri dari pengaruh Gereja dalam berpolitik.

\footnotetext{
30 Warnick, "Argument Schemes and the Construction of Social Reality."

31 Ibid.

32 Ibid.
} 


\section{Pidato Kennedy dan Kode Persamaan dan Toleransi Agama}

Saat menggunakan pidato dengan kode persamaan hak, Kennedy menggunakan sumber-sumber yang menarik perhatian audiens untuk memahami persamaan hak. Misalnya dalam aturan berkeadilan di Amerika Serikat, disebutsebut persamaan hak adalah ketika seorang individu diperlakukan sama dalam hukum dan pemerintahan. Kennedy menggunakan sumber konstitusi ini dalam pidatonya, tetapi juga menggunakan konteks Kekatolikannya dengan "Credo a la Kennedy." Misalnya, Kennedy kerap menggunakan kalimat "Aku percaya" pada persamaan hak pada konstitusi Amerika Serikat, seperti berikut ini:

I believe in a President whose religious views are his own private affair, neither imposed by him upon the Nation or imposed by the Nation upon him as a condition to holding that office..$^{33}$ (Aku percaya akan seorang Presiden yang pandangan agamanya adalah kepentingan privatnya sendiri, bukan memaksakan apa yang dia percaya pada sebuah bangsa atau memaksakan bangsa padanya sebagai cara untuk mengerjakan tugastugasnya).

Dalam pidatonya ini, JFK menggunakan Kode persamaan yang merupakan strategi untuk membangun argumen menggunakan esensi atau aturan tentang persamaan hak dalam hukum, pemerintahan, dan bahkan pemilihan presiden untuk menduduki kantor publik. Kennedy menggunakan cara dimana dalam suatu peraturan peradilan, seseorang harus disamakan kedudukannya. Melalui cara ini ia menekan perbedaan di antara keduanya dan meningkatkan pandangan mengenai kesamaan yang mereka miliki. Pidato ini membuat para audiens berpikir, jika mereka tidak ingin Presiden memaksakan kehendak agamanya dalam suatu Negara, maka sebaliknya Negara (dalam arti rakyat) juga sebaiknya tidak memaksakan kehendak kepercayaannya pada individu yang ingin menduduki posisi sebagai Presiden.

Selain itu, menggunakan pola yang sama, JFK terus menerus mengingatkan mengenai apa landasan Negara ini. Melalui strategi yang demikian, publik diberikan suatu pendidikan mengenai filosofi Negaranya dan melihat suatu isu keagamaan untuk seorang pejabat publik dengan proporsi yang lebih berimbang dan bijak. Dalam kasus ini, misalnya, JFK menyebutkan:

\footnotetext{
${ }^{33}$ Kenneddy, "Address to the Greater Houston Ministerial Association."
} 
Finally, I believe in an America where religious intolerance will someday end, where all men and all churches are treated as equals, where every man has the same right to attend or not to attend the church of his choice, where there is no Catholic vote, no-Catholic vote, no bloc voting of any kind, and where Catholics, Protestants, and Jews... will refrain from those attitudes of disdain and division... and promote instead the American ideal of brotherhood. ${ }^{34}$ (Akhirnya, Aku percaya akan sebuah Negara Amerika dimana tidak adanya toleransi antar agama akan berakhir suatu saat nanti, dimana semua manusia dan semua gereja akan diperlakukan sejajar dan sama, dimana setiap manusia memiliki hak yang sama untuk menghadiri gerejanya atau tidak menghadiri gerejanya sesuai keputusannya, dimana tidak ada lagi pemilih kelompok Katolik, pemilih kelompok bukan Katolik, tidak ada blok pemilih dari mana pun, dimana Katolik, Protestan, dan Yahudi akan menghentikan perilaku yang memisah-misahkan dan mengkotak-kotakkan, dan justru mempromosikan idealisme persaudaraan Amerika.)

Dalam pidatonya ini, terlihat sekali bagaimana JFK berupaya untuk mengangkat isu toleransi agama dan persamaan hak dalam bermasyarakat. Strategi ini berguna untuk meletakkan dasar kesadarannya akan nilai-nilai yang seharusnya dijunjung masyarakat Amerika Serikat dalam penghormatan akan keadilan dan perlakuan yang sama dalam hukum dan pemerintahan. Salah satu cara untuk mengangkat hak-haknya sendiri sebagai warga Negara, tetapi pada saat yang sama mengedukasi masyarakat untuk kembali pada dasar dan filosofi hukum suatu Negara.

\section{Konteks di Indonesia dan Kekristenan Ahok}

Berbagai pidato dan temu masyarakat menunjukkan kemampuan Ahok untuk berorasi dengan bersemangat dan terkenal cukup to the point. Beberapa pihak menyebut, bahwa Ahok cenderung tidak dapat menjaga tata karma, terlalu arogan, dan kontroversial. Meskipun adapula yang setuju dengan kemampuan oratorik Ahok yang tidak jaim, atau jaga image. Di satu sisi, Ahok juga sering menggunakan sejarah Indonesia, aturan dan perundangan di Indonesia, interpretasi Alkitab yang dapat digunakan secara universal, hingga kondisi sosial

${ }^{34}$ Ibid. 
dan agama di Indonesia. Tidak dapat dilihat pola yang sama dalam gaya retorika Ahok seperti JFK. Tetapi dalam berbagai kesempatan, Ahok sering menunjukkan kode retorika yang sama dengan JFK, yakni kode persamaan hak dan kode mengenai toleransi agama.

Kode persamaan hak dan toleransi agama membantu Ahok untuk memperoleh kesempatan untuk masuk dalam area pemilihan publik berdasarkan kesadaran kontrak sosial masyarakat. Pada saat pembangunan Negara Indonesia yang berlandaskan Pancasila dan menganut paham demokrasi, maka kesetaraan hak dalam hukum dan pemerintahan juga merupakan elemen penting dalam pandangan Negara ini. Sementara, toleransi agama merupakan nilai yang sewajarnya dianut oleh warga Negara Indonesia yang majemuk dan mengakui demokrasi.

\section{Pidato Ahok dan Kode Persamaan dan Toleransi Agama}

Ketika menggunakan Kode persamaan hak dan toleransi agama, Ahok menggunakan sumber-sumber yang ada di sekitar masyarakat. Sumber-sumber itu dapat berupa common sense atau asumsi umum, general history atau sejarah umum yang diketahui kebanyakan orang, hingga aturan umum yang berlaku dalam masyarakat awam. Kode persamaan menggunakan asumsi bahwa semua orang diperlakukan sama dalam hukum, pemerintahan, dan jabatan publik. Menggunakan diskursus sejarah, Ahok berasumsi bahwa ketika menjabat dalam ranah publik, semua sama apapun agamanya. Memimpin dengan agama tidak dapat membantu atau menjamin keberhasilan dan efektifitas kepemimpinan publik. Misalnya Ahok menyebutkan, "Kita urus negara begini majemuk pakai agama enggak bisa dong! Di sini sesama agama saja berantem. Sejarah sudah buktikan kok. Sesama agama saja saling ribut." 35 Pada kode ini, Ahok menunjukkan proses pengaturan Negara perlu memiliki asas hukum yang jelas. Jika konstitusi mengarah pada Pancasila dan UUD 45 maka itulah dasar hukum dan kesamaan hak perlu diletakkan.

Salah satu pernyataan Ahok yang cukup berani adalah dengan mengakui sekularisme Indonesia. Banyak pernyataan pejabat yang lebih suka menggunakan kata "nasionalis" dari pada kata "sekuler" karena konotasi sekuler

\footnotetext{
35 Rimadi, Ahok: Silahkan Sebut Saya Sekuler, UUD 45 Menganut itu.
} 
yang berlawanan dengan agama. Tetapi harus berani diakui bahwa Indonesia memang sebenarnya adalah Negara sekuler, yang memisahkan agama dan kepentingan publik. Pernyataan itu misalnya: "Silakan saja, sebut saya sekuler. Kamu jangan salah, negara kita menganut itu lho. UUD 45 menganut itu." ${ }^{36}$ Ini adalah salah satu pernyataan Ahok yang berani menyebutkan bentuk Negara Indonesia yang sekuler meskipun memiliki pengaruh agama yang kuat. Dengan menggunakan wacana UUD 45, Ahok menunjukkan sumber pendukung kode retorika yang dekat dengan masyarakat yang memisahkan agama dan politik. Pada pasal di UUD 45, sudah merupakan pengetahuan umum yang menyebutkan pemisahan agama hingga persamaan hak dalam hukum dan pemerintahan.

Kode toleransi agama juga muncul dalam dokumentasi pidato Ahok atau dalam acara temu masyarakat. Misalnya Ahok menekankan hubungan antara kemampuan toleransi, kemajuan suatu Negara, dan mengurusi hal-hal esensial yang berhubungan dengan publik dan kapabilitas kepemimpinan. Misalnya Ahok menyebutkan, "Ini Negara, kalau saya kebetulan saya tidak bisa menjadi imam di masjid, ya cari imam yang lain, gitu lho. Nah kita itu konflik di situ. Itu yang membuat Negara kita tidak maju." Disini Ahok menunjukkan bahwa masyarakat perlu bertoleransi satu sama lain dan bertoleransi kepada pejabat publik itu sendiri.

Ahok juga menggunakan kode persamaan perlakuan yang tidak didasarkan pada identitas agama, tetapi identitas kelakuan yang menjadi standar keimanan seseorang. Ahok menyebutkan, "Kamu mau tunjukkan iman kamu? Tunjukin perbuatan kamu, baru kemudian aku tahu iman kamu seperti apa." ${ }^{37}$ Wacana retorika ini secara sermonic juga mirip dengan diskursus dalam Kitab Suci dan nilai keagamaan yang dianut oleh Ahok yakni kekristenan, seperti "Iman tanpa perbuatan adalah mati" 38

${ }^{36}$ Luqman Rimadi, "Ahok: Silahkan Sebut Saya Sekuler, UUD 45 Menganut itu," Liputan 6. (21 Februari 2013) http://news.liputan6.com/read/517936/ahok-silakan-sebut-saya-sekuler-uud45-menganut-itu (Diakses pada 7 September 2013).

37 Rimadi, Ahok: Silahkan Sebut Saya Sekuler, UUD 45 Menganut itu.

38 Yak 2: 14-16, Alkitab Sabda, http://alkitab.sabda.org/passage.php?passage=yak\%202:14-26 (Diakses pada 8 September 2013). 


\section{F. Penutup}

Indonesia adalah Negara demokrasi yang terbesar ketiga di dunia. Demokrasi dapat berkembang dengan penerimaan publik terhadap tokoh dan pemimpin publik yang bukan dari kalangan mayoritas. Oleh sebab itu, kemampuan retorika pemimpin publik dari agama minoritas sangat diperlukan untuk menyampaikan pesan positif pada masyarakat.

Mempelari kode retorika mengingatkan kita, bahwa suatu wacana retorika tidak berasal dari suatu kondisi yang vakum, artinya ada teks lain yang dikonstruksikan untuk membangun strategi retorika yang mampu meyakinkan publik. ${ }^{39}$ Dalam kasus ini adalah mengenai retorika para pemimpin publik di Indonesia yang berasal dari agama minoritas. Melalui pemeriksaan kode retorika, misalnya kode pemisahan, kode persamaan hak dan toleransi ini, dapat terlihat bahwa kritik dapat memdekonstruksi interaksi antara teks retorika yang satu dengan yang lain untuk menciptakan wacana publik. ${ }^{40}$

Kode retorika JFK yang diaplikasikan dalam konteks Indonesia terutama mengambil contoh Basuki Tjahja Purnama merupakan salah satu cara untuk memahami skema retorika. Skema ini dapat dipelajari dan diaplikasikan oleh para pemimpin publik dari kelompok minoritas untuk maju dalam kancah politik. Thomas Farrell mengungkapkan bahwa retorika adalah sebuah kolaborasi seni yang mengarahkan dan membimbing suatu keputusan dan judgement, ${ }^{41}$ maka skema kode politik menjadi penting sebagai fungsinya untuk menyampaikan komunikasi politik yang efektif dalam membentuk image yang diinginkan. Semoga semakin banyak pemimpin dari kelompok minoritas manapun yang turun dalam politik praktis dan mengabdikan kemampuannya bagi Negara. Tidak lupa pula, keberadaan pemimpin minoritas ini mampu mengedukasi masyarakat mengenai arti demokrasi dan sekaligus menunjukkan pada dunia internasional bahwa demokratisasi di Indonesia mampu berjalan dengan selaras.

\footnotetext{
39 Warnick, "Argument Schemes and the Construction of Social Reality."

40 Ibid.

41 Thomas B. Farrell, Norms of Rhetorical Culture (New Haven, CT: Yale U. P, 1993).
} 


\section{DAFTAR PUSTAKA}

"Ahok: Alasan saya tidak pindah agama Islam karena...," Youtube, (21 Juli, 2013), https://www.youtube.com/watch?v=35v6NgIcx18 diakses pada 7 September 2013.

“Basuki Cahya Purnama," Merdeka.com, (2012), http://profil.merdeka.com/ indonesia/b/basuki-tjahaja-purnama/ diakses pada 27 Maret 2013.

"Sudutkan Jokowi Ahok, Rhoma Irama dipanggil Panwaslu," JPPN.com (1 Agustus 2012), http://www.jpnn.com/read/2012/08/01/135539/SudutkanJokowi-Ahok, -Rhoma-Irama-Dipanggil-Panwaslu- (Diakses pada 5 September 2012).

“The Nature of Government," American Government. (2008-2013).http://www. ushistory.org/gov/1d.asp diakses pada 23 Mei 2013.

"What is Rhetoric?" Bringham Young University. (http://rhetoric.byu.edu/ encompassing\%20terms/rhetoric.htm diakses pada 20 Mei 2013.

"What is Rhetoric?" Bringham Young University. (http://rhetoric.byu.edu/ encompassing\%20terms/rhetoric.htm diakses pada 20 Mei 2013.

Al Rise dan Jack Trout. 1993. Positioning: The Battle for Your Mind. New York: McGraw Hill.

Anderson, Karrin Vasby.2011. "' Rhymes with Blunt': Pornification and US Political Culture," Rhetoric \& Public Affairs 14, no. 2 (2011): 327-368.

Aziza, Kurnia Sari. 2012. “LSI: Jokowi Basuki 53,81 persen dan Foke-Nara 46,19 persen, " Kompas.com (20 September 2012), http:/ / megapolitan.kompas.com/read/2012/09/20/20285279/LSI.Jokowi-Basuki.53.81.persen.Foke-Nara.46.19.persen diakses pada 5 September 2013).

Farrell, Thomas B.. 1993. Norms of Rhetorical Culture. New Haven, CT: Yale U. P. Fessler. 1983. "Ronald Reagan, Address to the National Association of Evangelicals ('Evil Empire Speech') (8 March 1983)"

Frank, David A..2009. "The Prophetic Voice and the Face of the Other in Barack Obama's' A More Perfect Union' Address, March 18, 2008," Rhetoric $\mathcal{E}$ Public Affairs 12, no. 2 (2009): 167-194.

Frank. 2008. "The Prophetic Voice and the Face of the Other in Barack Obama's' A More Perfect Union' Address, March 18, 2008."

Kennedy, John.1960."Address to the Greater Houston Ministerial Association”, American Rhetoric, September 12, 1960. 
Medhurst, "Mitt Romney,' Faith in America,' and the Dance of Religion and Politics in American Culture."

Medhurst, Martin J..2009. “Mitt Romney,' Faith in America,' and the Dance of Religion and Politics in American Culture," Rhetoric \& Public Affairs 12, no. 2 (2009): 195-221.

Moraga, Cherrie and Gloria Anzaldua. 1981. This bridge called my back. New York: Women of Color Press.

Paul Fessler, "Ronald Reagan, Address to the National Association of Evangelicals ('Evil Empire Speech' 8 March 1983)” (2009), http:/ /archive.vod. umd.edu/documents/Fessler-Reagan.pdf.

Perehnan, Chaim and Lucie Olbrechts-Tyteca. 1969. The New Rhetoric: A Treatise on Argumentation, frans. John Wilkinson and Purcell Weaver. Notre Dame: U of Nofre Dame P, 1969, p. 187-459.

Purnomo, Heri. 2013. “Ahok: Antara Konstitusi, Kitab Suci dan Konstituen, " Kompasiana (27 Agustus 2013), http://sosok.kompasiana. com/2013/08/27/ahok-antara-konstitusi-kitab-suci-dan-konstituen587588.html diakses pada 7 September 2013.

Rimadi, Luqman. 2013. “Ahok: Silahkan Sebut Saya Sekuler, UUD 45 Menganut itu,"Liputan 6. (21 Februari 2013) http://news.liputan6.com/read/517936/ ahok-silakan-sebut-saya-sekuler-uud-45-menganut-itu (Diakses pada 7 September 2013).

Warnick, Barbara.1996. "Argument Schemes and the Construction of Social Reality: John F. Kennedy's Address to the Houston Ministerial Association," Communication Quarterly 44, no. 2 (1996): 183-196.

Watzlawick, Paul, Beavin-Bavelas, J., Jackson, D.. 1967. Some Tentative Axioms of Communication. In Pragmatics of Human Communication - A Study of Interactional Patterns, Pathologies and Paradoxes. New York: W. W. Norton.

Wright, Jeremiah A. 2008. "Confusing God and Government," http://www.blackpast.org/?q=2008- rev-jeremiah-wright-confusing-god-and-government accessed October 14, 2008.

Yak 2: 14-16, Alkitab Sabda, http://alkitab.sabda.org/passage.php?passage=yak\%20 2:14-26 diakses pada 8 September 2013. 